\title{
ERRATUM
}

\section{Alveolar capillary dysplasia with misalignment of pulmonaryz veins: concordance between pathological and molecular diagnosis}

Y Castilla-Fernández, C Copons-Fernández, R Jordan-Lucas, Á Linde-Sillo, I Valenzuela-Palafoll, JC Ferreres Piñas, A Moreno-Galdó and F Castillo-Salinas

Journal of Perinatology (2014) 34, 166; doi:10.1038/jp.2013.160

Correction to: Journal of Perinatology (2013) 33, 401-403; doi:10.1038/jp.2012.63

Following publication of this paper, the authors noticed that 'pulmonary' was misspelled in the title. The correct title appears below. The publisher regrets the error.
Alveolar capillary dysplasia with misalignment of pulmonary veins: concordance between pathological and molecular diagnosis 